International Journal of Linguistics, Literature and Translation

ISSN: 2617-0299 (Online); ISSN: 2708-0099 (Print)

DOI: $10.32996 / \mathrm{ijllt}$

Journal Homepage: www.al-kindipublisher.com/index.php/ijltt

\title{
Image Politics and the Construction of Public Opinion: Readings into the Arab Spring Context
}

\author{
Mariem HIMMI 8(D) \\ Department of English studies, literature, art, and pedagogical engineering Laboratory, Ibn Tofail University, Kenitra. Morocco \\ $\triangle$ Corresponding Author: Mariem HIMMI, E-mail: mariemhimmi@gmail.com
}

\begin{tabular}{|c|c|}
\hline ARTICLE INFORMATION & ABSTRACT \\
\hline Received: September 08, 2021 & \multirow{7}{*}{$\begin{array}{l}\text { Images are ubiquitous in today's modern society. They tend to be taken for granted } \\
\text { and their power is underestimated. However, images do not just reflect the world } \\
\text { around us, but they construct reality. They can be inspirational and ideological, as they } \\
\text { can trigger a political conscience. They now accompany every occurring event; they } \\
\text { update and form the public. The Arab Spring context represents an image-saturated } \\
\text { revolution wherein images have proved to be an effectual weapon and a catalyst of a } \\
\text { massive public reaction and mobilization. The present paper studies images as a } \\
\text { medium that is loaded with messages and is capable of shaping public opinion. It } \\
\text { explores the different meanings encoded within these images, as it analyses their } \\
\text { effectiveness on the public during and after the last Arab uprisings. The paper also } \\
\text { ponders upon the reason why some images raise multiple reactions, and push leaders } \\
\text { and masses to action. }\end{array}$} \\
\hline Accepted: October 14, 2021 & \\
\hline Volume: 4 & \\
\hline Issue: 10 & \\
\hline DOI: 10.32996/ijllt.2021.4.10.1 & \\
\hline KEYWORDS & \\
\hline $\begin{array}{l}\text { Image politics, public opinion, the } \\
\text { Arab Spring, social media, } \\
\text { discourse analysis. }\end{array}$ & \\
\hline
\end{tabular}

\section{Introduction}

In a mediatised world, the public has gained more leverage in decision-making and has become one of the leaders' worst nightmares. It demands to be consulted, informed, heard, and respected. No more unilateral decisions can be made without inciting public opinion. Public opinion can, now, oppose or reinforce a decision. One of the tools used to tame the public is the media. This latter found in images the most rapid and accessible way to reach the largest public and thus construct a certain general opinion on what happens in the world. Being at the service of media, the image manipulates, influences the public, and pushes it to react. Images have lately become one of the triggers of social and political movements. The Arab Spring was no exception. It, in fact, presents a perfect context of how images played a crucial role in mobilizing the masses and forming a global public opinion. The selection of this case study results from the powerful images that $\mathrm{l}$, as a follower of the Arab Spring, have been bombarded with on different types of media. These images are very provocative and incentive of public opinion. This phenomenon is not new but recurrent; thus, it is important to understand why images, more than any other medium, are able to form a public opinion as such.

\subsection{Motivation and methodology}

The images I used in this paper are for the sake of illustration. They are images that were under the spot in social media during and after the Arab Spring fever and were able to raise people's sentience and mark the public memory. Some of them made history and were able to tell a story, summarize a situation, and to point out an existing but often neglected issue. The paper follows a qualitative content analysis methodology that analyses both the form and content of the image in relation to its context. The content analysis aims to analyze the presence of certain concepts, messages within a certain content, and to infer meaning out of it. It also helps to make a link between the cause and the effect, i.e., between content and an audience. Images are one of the best choices to lead such a study.

\section{K C AL-KINDI CENTER $\mathbf{R}$ D FOR RESEARCH AND} Your gateway to world-class research

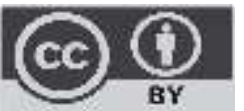

Published by Al-Kindi Center for Research and Development, London, United Kingdom. Copyright (c) the author(s). This open access article is distributed under a Creative Commons Attribution (CC-BY) 4.0 license 


\section{The mechanics of the image}

Joly (1994) defines the term 'image' as "something that looks like something else". It may not be visual in all cases, yet it alludes to something visual, depending on the subject, whether imaginary, abstract, or real. An image moves from someone who produces it to someone who recognizes it; in Barthes' words (1981): an operator and a spectator. The term image is intensely polysemous. It refers to subjects that are sometimes concrete, other times abstract, and whose technical supports are disparate. In other words, an image can come in the form of a photograph, a painting, a statue, and in other visual forms, and depict something real or unreal. For Sartre (1936), "an image is an act and not a thing". It is, therefore, content in the conscious whose object exists in the imagination and not in the present reality. It allows the conscience to escape the real, to set free, and to retreat from the reality which it denies. It is only there where people can manifest their freedom equally. Sartre approaches the image from an intentional perspective. For him, it is the intention that gives sense and creates the unreal. Even when he tackles photography, he projects on it the meaning given by the viewer. This latter has the power to form images and, thus, recognizes the power of reproduction and the resemblance effects an image has. The object represented in a photograph exists only because the viewer puts it there. It is the spectator who produces the identification and substitutes the material image with the mental one. Sartre adds that the object of the image is absent and null. The power of the image conscience, then, resides in its ability to nullify what is being imagined. The object is formed in the material world but then chased from it. No matter how alive and touching an image can be, its object does not exist. That said, Sartre does not deny the spontaneity and creativity attributed to the image in the artistic activity. Abdelkebir Khatibi (1971), on the other hand, rejects the idea of separating the image from what it represents. For him, representation has its own cultural existence that cannot be easily disregarded. As a native of a culture of signs, he believes that signs are also images since they are traces of the cultural imaginary of a society. They belong to the collective memory and are present in the body, the gaze, and gestures. Henceforth, an image can be defined as the visual future of writing that comes in shapes and colors, that can be done and undone in order to construct an imagination.

The successive improvement of photography and cinema made the dream of a 'seizable' reality possible. These types of images are believed to offer a copy of the world. The technical peculiarities of these two arts or forms of seeingare what nominated them as heirs to naturalism. Hence, it is not surprising to see the image at the service of information. In his essay, The Photographic Message, Barthes (1980) makes some observations on the press image as well. He believes that "the press photograph is a message"; The message itself is a combination between "a source of emission, a channel of transmission and a point of reception" (Barthes, 1980, p.15). Barthes explains that in the case of the press photograph, the source of emission is the newspaper staff who captured the photo and worked on it. The channel is the newspaper itself, while the receiver is the reader obviously. Moreover, the press photograph is composed of two structures, a photograph and a text (mainly an article, a title, or a caption). The two structures complement each other and co-operate to transmit information. Therefore, the press photograph carries a linguistic and visual message simultaneously. In fact, the informative image considers the author/producer a witness and the image an index. It provides a record, diagnosis, and information about the world, rather than a personal vision of the one behind the camera. It is believed that the role of the author in picture taking is normally not as dominant as other authors' may be. It may even be said to be irrelevant. This takes us back to Barthes (1977), on how an author's death is pronounced the very moment their idea is born. The main element within an image resides in the subject. Therefore, once an image has been taken, the photographer disappears. However, the role of the author cannot be totally ignored, knowing that a camera cannot choose what to record by itself; it needs an operator to position it, to decide on what to frame and what to eliminate. Indeed, the dependence of the information industry on images is a very good sign of the importance of this latter. Baudelaire (1955) seems to disagree with such claims and denounces photography as the mortal enemy of art. He believes that art is a process of imagination to produce beauty. Since photography is industrial and material, it can never reproduce that beauty. He denigrates photography as an art since it provides exact details instead of allowing an imaginative and dreamy creation. Therefore, only untalented artists can substitute painting with photography, and once done, the death of painting is declared. He expresses his anxiety concerning the growing success of photography among the public and painters themselves, stressing the fact that art is about dreaming and not simply seeing.

\subsection{The image as a representation}

Therefore, an image is far from being just a thing or a representation; it is never neutral nor natural but rather constructed. Images are responsible for the way we perceive and build up our personal understanding of the world and how it works. The invasion of media images, in our days, conditions the way we look at the world. This gaze is manipulated by a certain ideology that dictates where, how, and what to view. Both the maker and the receiver of the image are pre-exposed to a multitude of images that turn their way of looking to a cultural process, known as the gaze. It is pre-constructed with interpretations, attitudes, and conclusions already built-in. An image is imbued with meanings that are negotiated by the maker and the viewer. In fact, this debate over the ontology of the image is not recent and has started ages ago. In our modern time, an image derives its value from the amount of information it carries and its accessibility to a larger audience. Media, nowadays, contribute to their quick circulation. An image's immediacy to depict a certain event is what makes its value now. Its ability to travel the borders, touch on different audiences and become the 'picture of the day' is what makes it important, and the number of views and shares on social media is a sign of its success and worth. The Arab Spring revealed the importance of social media in sharing information with the larger public, and its 
contribution to the construction of public opinion. Revolution has started virtually before it moved to the streets. The circulation of information through hashtags on Twitter or images on Facebook and videos on YouTube served as a vehicle to motivate people to keep up the uprising. Whether in Tunisia, Egypt, or other countries, the use of the internet and especially social media platforms was prominent and helped in sharing images and influencing the public both locally and globally.

From a semiological point of view, the interest in an image lies in its significance and how it generates meaning. What needs to be remembered is that an image is heterogeneous. It gathers within a frame different categories of signs, colours, form, texture, words, etc. The interaction between these different signs is what makes it possible to decipher and understand an image. The notion of analogy or resemblance within an image is what makes it a representation. Resemblance or likeness does not mean exactness but a close representation of the thing. Accordingly, representation is highly debatable in visual arts. It, first, refers to the use of a language, whether written or visual, to create meaning about the world that surrounds us. Words and images are used to describe, understand or give meaning to what we live. Like any other system, this linguistic and visual process of representation is structured by rules and conventions. However, attaching representation to imitation and mirroring is problematic. The use of language, including images, to define reality implies that we contribute to constructing that reality and in attributing meaning to it. Language does not only reflect an already existing reality, but rather mediates, constructs, and organizes our understanding of the world, reality, and imagination. In this respect, images have always been used to represent, create meaning and convey messages. They were used to express real, imaginary as well as abstract concepts. Peirce divided the sign into three types: index, icon, and symbol. The index implies a trace of something that happened, while the symbol relies on convention. As for the iconic sign, it enforces a qualitative resemblance between the signifier and the signified. It imitates or reuses a certain number of qualities of the object such as colour, form, and texture to make a 'visual image'. The quick transmission and connotative (political, cultural, or social) weight of an image render it an icon. During the Arab Spring, images of Mohamed Bouazizi crossed the borders of his native town Sidi Bouzid to reach the different cities in Tunisia. Considered as the inspirer of the Arab Spring revolutions in the MENA region and middle East, his picture occupied the streets of Tunisia and replaced the former president Ben Ali's. Similarly, a more recent example from the American riots in 2020, is the images of George Floyd which flooded social media as his live arrest and death incited national and international outrage. Floyd has become the icon of the Black Lives Matter movement in the USA, his picture occupied the streets and walls of the whole country and sparked movements of solidarity worldwide. He has become a symbol of the continuous segregation exerted on the Afro-American community in the USA, and the martyr of racial inequality and police abuse. Following Peirce's (1894) definition of what a sign is, such images surpass being a mere analogy or a resemblance to become part of the cultural and collective memory of the nation. They stand as a reminder and a witness of historical events. Throughout images, both Bouazizi and Floyd are forever immortalized in the public conscience in particular, and that of the world as a whole.

\section{The construction of public opinion}

As much as the public occupies a pivotal social and political position and its heavy presence is tangible, as much as it is invisible. Consequently, it becomes difficult to define. Britannica defines public opinion as "an aggregate of the individual views, attitudes, and beliefs about a particular topic, expressed by a significant proportion of a community". In other words, public opinion is a collection of different people's opinions and views on a certain issue. The term public opinion dates back to the sixteenth century when for the first time it became important to know what people think, but it only developed with the famous philosopher Jeremy Bentham who believed that public opinion is powerful and can influence leaders. As for Jürgen Habermas (1964), he connected public opinion to the public sphere where opinions can be expressed, discussed, and formed regardless of social ranks; thus, public opinion is very ubiquitous in the political arena. Aware of its importance, leaders make sure to counsel it before passing their policies. However, public opinion remains vulnerable and easily influenced.

\subsection{The role of media in public opinion}

No doubt that public opinion can be manipulated, and what other medium to do so than mass media. Conscious of the power of such technology, politicians adhered to the game and adopted media to circulate their agendas and ideologies. One of the tools that media use to manipulate public opinion is stereotypes. Shadowing any other type of extremism, Islamic extremism has become the media's best topic of interest during the Arab uprisings. Any incident, no matter how accidental, is linked to Islam and Muslims. Responsible for the hate discourse that never ceases among different cultures, the media makes no attempt to ease it. Being in constant exposure to what they see on their TVs and social networks, a lot of people are being indoctrinated. They have absolute trust in what they see, that is the reason why media agents play on the immediacy of images and their closeness to reality to influence the viewers. In opposition, those who are aware of the puppeteering work that media exercises on the public, use the same media to counterattack prejudices, propaganda and stereotype. Whether in the west or in Morocco, social networking has become more than a socializing space. It has drifted from its primary function and has become a space where anyone can express their opinions and push others to take a stand. At present, social networking complements street activism before descending to the street to manifest, militate, and voice their rights. Social networks have become a place to 
gather, congregate, and start manifestation before taking it to the 'real' world. Believed to be a mere 'virtual' world, one that is closer to a non-existing and imaginary world, it has now proven to be one of the most impactful worlds.

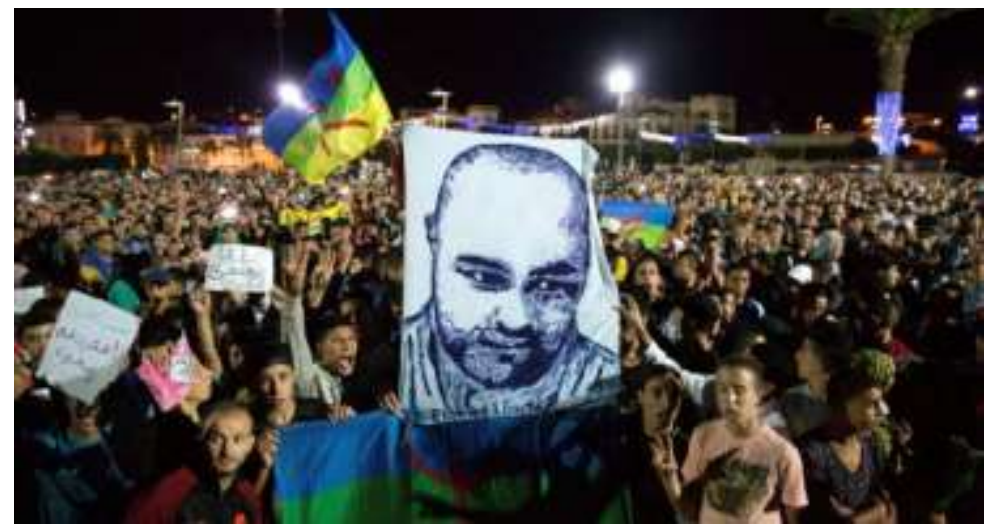

Fig. 1: Protestors take part in a rally after the death of Mouhcine Fikri, Morocco, 2016. (Source: google)

Not long time ago, authorities used to easily control and handle the masses who chose to go to the street. Now, forces are engaged to spy on, infiltrate within groups to get to know their future steps. Despite all attempts to do so, the power of the group proves to be indestructible. Interestingly, the public's answer and reaction to the demands of such activist groups is fast. Not only that but demands now reach the larger public(s). The incident of the Moroccan fish vendor in 2016 (fig. 1) who died under suspicious circumstances and in an indecent way is a good example of how media contribute to influencing the public. The very moment the image of the incident was shared on Facebook and other social media, the public's rage became uncontrollable. People circulated hashtags with the man's name, sketches of the image were made and took the place of profile pictures, and instant calls to revolt were made. Consequently, different cities of Morocco went to the streets to claim for rehabilitation. The whole country spoke in one voice. The rapidity in which the image of the deceased 'street vendor' traveled the web was unbelievable. In fact, one image sufficed to trigger public congestion.

The success of such images and the public's quick reaction to them is related to the general situation in which the event captured on the image took place. A politically and socially pre-tensed situation contributes to the fast absorption and interaction with the image. People are sensitive to and easily affected by what those images represent. In the case of Morocco, the picture of Mouhcine Fikri, the fish vendor, came at a time when people felt that they are being oppressed and their rights are denied. The way this man died, 'grinded' in a garbage truck was enough to inflame the situation which justifies the different street manifestations and calls to unite and stand against arbitrariness. Semiologically speaking, the image of the late vendor becomes a symbol of resistance to injustice and revolt, just as Bouazizi's image in Tunisia who sparked the Arab Spring in 2010 had become a national icon.

\subsection{Media as an ideological tool}

The aforementioned fish vendor incident uncovered the political interference within the visual field. Politics has the ability to adopt any medium that serves its motives. Needless to say, media is governed by rules that are set by politics. They interfere with the way we look at things and the way they are presented to us. Media, images included, is used to transmit ideologies, conceptions, and concepts. Many governments have done without the military force to pass on some ideology. They have now resorted to visual art, music, and other soft powers to control and to exert their hegemony over the world. A very simple example can be drawn from elections. It is outstanding and sometimes funny how different parties use images or even work on 'their image' to approach the public. Politicians from different parties use images to confirm an action, to show a certain behaviour, or to even attack each other. Aware of the importance of social media in circulating images and in reinforcing or rebuking them, politicians race to reach the public and encourage them to vote for them. In the same respect, a war of images was started where different parties were ridiculing each other through the use of their mutual images. Funny enough, those politicians work with images to construct or destruct their own or other's images. Therefore, the image is used to serve self-image.

\section{The image as a constructor of public opinion}

"The images that mobilize conscience are always linked to a given historical situation. The more general they are, the less likely they are to be effective" (Sontag, 1977, p.17). In other words, the context adds to the image's effectiveness. That is the reason why some images affect us as viewers more than others. Whenever the right context and feelings are set, the public becomes more ready to accept the image. Images, then, can be responsible for constructing a public position. In addition to context, images may sum up a whole event in a slice of time; the whole event is then condensed generating a more powerful reaction to it. The public's familiarity with that issue represented in images is what makes that image visible and impactful, and the public is reactionary. Once the public identifies with the representation, political consciousness is settled. Nevertheless, the image shocks as long as it presents 
something new, while over-exposure to the same content reduces sensitivity and makes the image lose its emotional weight. The intentions of the photographer, therefore, have an opposite effect.

\subsection{Heroism of vision"}

The photographer is the number one agent who contributes to the process of the construction of a public opinion through images. No matter how impartial or non-interfering a photographer may be, they consciously or unconsciously participate in what they represent. The image is, then, not mere evidence of what is there but of what one sees; not only an observation but an evaluation of the world. Unlike ordinary people, photographers have what Sontag called "photographic seeing" (Sontag, 1973, p.89). They have this capacity to take pictures that would engage people not only to see but to perform. A successful photographer is the one who raises the receiver's interest in what they see. This requires a constant search and renewal of techniques, subjects, and ways of looking. A photographer becomes, then, more than a person who merely takes pictures. Since the invention of the camera, photographers have always engaged in an individual chase for images. This explains the brave and sometimes fatal work photographers and mainly journalists now do when they risk their lives into the deadliest conflict zones to bring the most actual and live images from all around the world. "Everything is in the instant now", said war photographer Paul Conroy, "battles have been influenced by the immediacy of information". The photographers' race for the 'fresh' and current 'picture of the day', despite the danger, is believed to have changed the world's views and affected the biggest decisions.

During the Arab Spring, mainstream media was shadowed, leaving the floor for citizen journalism and blogging to flourish. Yet, with the evolving conflicts, the world's press agencies had to adapt and mobilize their photographers to cover the stories and bear witness to what was happening. Those photographers played the role of heroes by adventuring and capturing people's rage and war atrocities on camera; their only but mighty weapon is the camera. When in the action, armed men and photographers are both warriors, but each fights their own war. If one fights for freedom and rights, the other fights to collect and share information. However, photographers' bias has always been put into question. Many doubt the objectivity of information and images that were taken in a time of war or political confrontation. No matter how transparent a piece of information or an image can be, it cannot be denied that photographers bring their own perspective and gaze to what is being photographed. Barthes (1977) insisted on the fact that any author (whether a writer, a painter, etc.) projects their own background, feelings, emotions, intentions, desires, fears on what they produce. Their product is but a result of these internalized experiences that have been collected throughout one's life. Therefore, while writing, an author cannot but use them. No matter how realistic a work of art is, there is always an individual, subjective participation in it. In fact, the product already exists in the author's mind. Not only that but the author also leaves spaces for the receiver to complete and fill in. A work of art is, thus, a collective work between the author and the reader. The same applies to photography. While taking pictures, photographers bring their own contribution to the world/reality being depicted through angles, colours, framing, among other techniques. No matter how "natural" a picture looks, the angle from which it was taken, the frame that includes and excludes elements, the degree of light shed on it are not random. Human interference exists in every shot. It is sometimes meant to serve some agendas by predilecting some parties, groups, or cases over others. Photographs have then to be subject to investigation and scepticism. Not all what we get to see on TV, social media, newspapers, or else are good copies of 'what is there'; they sometimes make use of camera, photographic eye, and different techniques to distort, fake, deny or modify reality. Just as photographers are believed to be heroes that defy all dangers to bring truth, they can be enemies of truth. They can manipulate viewers and misuse their trust to show an 'unreal' reality in order to build a mistaken public view. Conroy asserts that journalists have to be cautious of what they realised to the viewer, "what we realized was that you are open to be used for propdouble-check you have to do is double check and get eye witness accounts."

\subsection{The subject also matters}

The subject matter is the inspirational reason behind the act of photographing. Whether contextualized or isolated from the context, it can shape the viewer's references, and affect them to different degrees. The complexity of photographic representation lies in the interplay between this subject, the context, the intentions, the interpretation, and perception. In other words, the power of the image resides in the relation between the subject matter and the ways of looking; and it is that power that impacts public opinion. The photographer chooses an object in the first place, whether human or other, and makes it subject to their vision, techniques, and camera. This is how an object alters from being an object to become a subject. Photography takes the whole world as its subject. Thus all kinds of tastes are acceptable. The viewer has the freedom to prefer an image over another, simply because taste in photography is more global, permissive, denying any difference between good and bad. Therefore, preferring an image over another does not imply its superiority or aestheticism, it rather implies the viewer's identification with the subject. Also, taste in photography is elusive; what was formerly dismissed because of its lack of composition may now be seen as creative. Indeed, photography escapes any classification or attempt to impose beauty or technical perfection standards on it. As a result, no subject or technique will qualify or disqualify an image. Sometimes, the most banal and simple subjects are chosen to shock and move the conscience. They are often about things or people that are around us but go unseen. Their defamiliarization by the artist is what makes the viewer interested, shocked, or impressed. This ability to see what others cannot see or ignore is what raises the viewer's 
curiosity. Barthes (1980) argues about the ability of "unary photographs" (p.41) to shock and traumatize. Such photographs transform reality without duplicating it.

Also, photography has always been the battlefield of two opposing fields: arts and science. While the first enhances its aesthetic characteristics, the latter emphasizes its rational and true value. A fake painting, for instance, would be thought to distort history while a fake photograph falsifies reality. Photographs have, now, become the standard of beauty. If one looks beautiful in a picture, then they really are. The opposite is also true. The camera has now become the measurement of someone's attractiveness or ugliness. In the same way, not all people have enough bravery to be photographed. It is so present in our lives that its overwhelming presence made it sacred, almost god-like. Everybody would behave appropriately in the presence of the camera. That feeling of being looked at, followed, surveilled, and judged through a picture is what makes people obsessed with looking good. George Orwell's 1984 is a good example of the dominance of the camera in people's lives. People would fake their own image to escape reproval. Our present situation may not be that extreme but whether we like it or not that is the truth. We should not forget that being the subject of the camera requires a lot of courage and self-confidence. It is an appropriation of one's own life and surrounding.

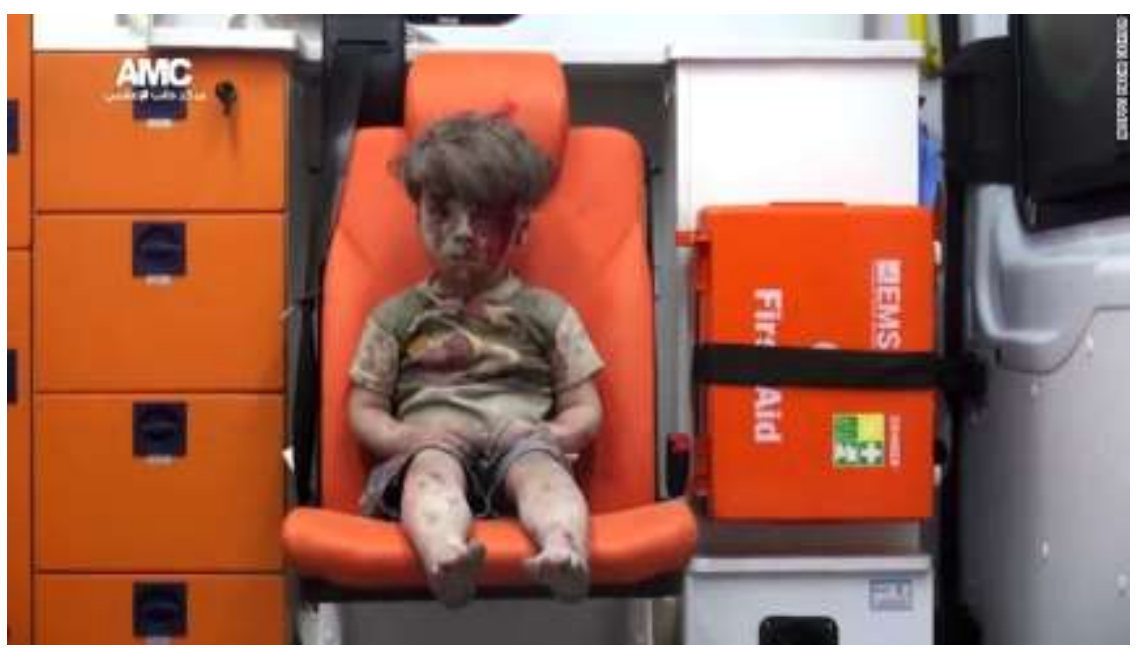

Fig. 2: Emran in the ambulance after the bombings in Aleppo, 2016 (source: Google)

Photogenia or beauty for photographers is everywhere, whether in embellishing the world or in unmasking it. It can sometimes be cruelty. Sometimes the cruelty of a scene taken in a picture is the reason why some people are moved. The picture of the Syrian boy Emran (fig. 2) is a good example of that. The boy apparently sits alone in what looks like an ambulance. The light clothes the boy is wearing suggest summer taking us to the bombings in Aleppo in summer 2016. The ugliness of a puzzled, lonesome little boy who has just survived a bombing attack that displaced his family is what makes this image beautiful; beautiful not in the literal meaning of the word, but in summarizing the atrocity of the war in Syria on civilians and on children in particular. The continuous bombings on this distressed city had made many victims. This long shot allows us to notice the absence of Emran's parents, which stresses the fact that this war has made a lot of orphans. The amount of space on both sides of Emran's body shows his small size in that big vehicle, just as his face coated with blood and dust makes him look like a camouflaged soldier. This only emphasizes the saddening reality of those children in the middle of that carnage, children who are forced to fight in order to survive. Indeed, it is that calm and innocent look on the boy's face that moves the viewer as much as it disturbs. His self-containment is as incomprehensible to us as it initiates chaos of questions in our minds. The beauty of this photograph resides in its success to reach our effect and eventually trigger our empathy. This photograph made the rounds on different media and spilled a lot of ink. It was able to unify public opinion on the barbarity of war in Syria and urge leaders to move. Also, the image transcended every cultural or religious border to affect the humane. Many would remember the CNN anchor's inability to contain her emotions when reporting the story of Emran, as well as the story of the American boy who wrote a letter to President Obama asking him to foster Emran. Additionally, the plain reality that the photograph of Emran depicted is one of the motives of photography. With the invention of the camera, the rapidity with which anything was recorded was a subject of both praise and despise. An image, at first, depicted reality accurately leaving nothing to be hidden. It was supposed to unveil hypocrisy and enlighten people. Consequently, this capacity of unmasking everything was blamed. A photograph did not only offer a realistic reality but a space for scrutiny and evaluation. Subsequently, the photograph has become a synonym of reality. This reality within photography is dubious. The camera has the ability to make reality affordable, controllable. The duplication of images and their availability is what attracts and provokes them at the same time. Contemplating a single image will carry the viewer to what is beyond the 
photographed. No matter how magnificent an image can be, the reality behind it is bigger. In fact, photographs are an invitation to meditation, speculation, and fantasy.

\subsection{Distorted context}

Context empowers the image since it is closely related to truth. The moral and emotional charge of an image relies on where it is used. A picture in a magazine is not the same as in a gallery or on the hallway wall. The different uses of the image are what make its meaning. This meaning can be dynamic which makes the truth relative; it changes depending on the context. These multiple truths render the image a vulnerable and easily forgotten entity.

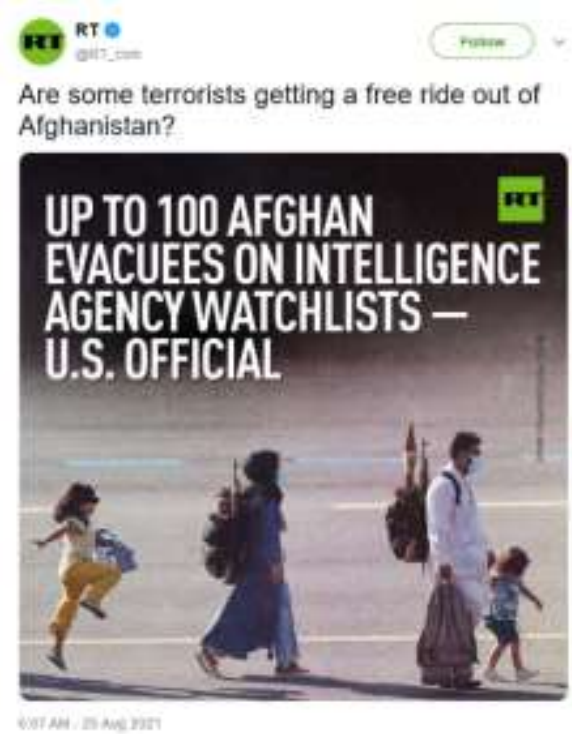

fig. 3: A tweet from RT, the Russian broadcaster in August 2021. (Source: RT/tweeter)

With the advent of technology, it has now become easier to detect touched photographs from those who are not, yet this very same technology can be used in an opposite direction to 'perfectly' fake images. The purpose of these trick effects is to present a faked product as if it were natural. They rely on the credibility of the photograph to pass twisted codes. Related to the Arab Spring context, several photographs were used to demonize the presence of refugees in western countries, for example. Such images were decontextualized to convey a different message. Recently, a picture posted by The Russian State Broadcaster (RT) about the return of the Taliban to Kabul made surface online and went viral portraying an Afghani family heading to the airport with their children while the parents carry weapons in their backpacks. The actual picture was taken in August 2021 when a family of refugees was fleeing Kabul to a safer destination. The picture was shared on social media and retweeted hundreds of times creating a sense of critique and shame. The broadcaster apologized by admitting it was photoshopped for the purpose of sarcasm but resulted in being of "bad taste". The picture was decontextualized, tricked, and used to claim that terrorists were being transferred to other countries under the mask of refugees. The signifier in this picture is the machine guns carried by both parents that have become a sign of terrorism, while the code is clearly ideological. That being said, context reinforces or undermines that reality. A decontextualized image loses every credibility since it fabricates a reality to serve ulterior motives. Only visually literate viewers are able to detect the falsifiability of such images

\subsection{What role for the public?}

We, as viewers, are immediately tempted into understanding the iconic message that appears as an image. This temptation is the outcome of perceiving the image as a close analogy of a given reality. What is reality after all? Each one of us has our own preconceptions of reality. What is 'natural' or real for one may not be for the other. Thus, no matter how close to reality a work of art looks like, it is not necessarily real. When looking at an image, viewers project their own feelings, beliefs, and knowledge. Therefore, perspective implies the use of angles. It is one of the ways through which the relation between the subject and the viewer is established. It implies that there is a certain subjectivity and individuality behind the choice of the subject matter. When producing an image, not only do we select a certain frame, as well as an angle of shot; in other words, a point of view. The frame limits our viewing of the image. It determines what to center and what to exclude as off-frame. The angle orients our vision. The eye becomes the lens, the camera that took the shot. The angle decides on the position of the viewer in relation to the subject. The different types of angles that exist are used intentionally to pass on a certain idea and to trigger a certain feeling in the viewer. Looking at a subject from an upper position is definitely not the same as looking at it from a lower one. The viewer experiences different feelings if looking at the same subject from different angles. The positions that the viewer takes in relation to the subject are a result of personal attitudes. The latter is socially motivated and determined by the viewer's surroundings. "The world in the 
picture was experienced as a direct continuation of the observer's own space" (Arnheim, 1974, p.274). The frame started to be used as an attempt to isolate a certain subject from its own environment and make the image a kind of "window on the world" (Kress, Von Leeuwen, 1996). Meanwhile, the viewer's point of view became important for a more complete image. Moreover, the text is also a prominent tool. The text comes to complete what the image fails to say. If a photograph is accompanied by a text, regardless of its form, this very text communicates certain information. The two structures co-operate despite being different (one being visual, the other linguistic). For instance, a press photograph often comes with a commentary or a caption. To have an overall understanding of that photograph necessitates a separate exploration of both structures.

\subsection{Reading between the lines}

"In photography, there is never art but meaning" (Barthes, 1977, p.24). This statement proposes that photography is not about Art for Art's sake but about what is behind it. There is no such a 'clear' or 'obvious' image. No matter how real it may look, there is something potent underneath. It is the message; the message empowers the image. It undertakes many processes before reaching the receiver. As far as photography is concerned, a photograph is the carrier of the message. It is the channel through which a message is conveyed. The knowledge of the receiver, the clarity or ambiguity of the message, the medium, the context, etc. is among the factors that decide the way the message is to be interpreted. The denoted message implies the absence of a "meaning full of all the meanings" (Barthes, 1977). It has one single meaning; the meaning that immediately comes out of the representation. This meaning is superficial and requires no prior knowledge of sociological and social in-depth. It comes in the form of colors, lines, and shapes. Among all images, the photograph is the only one capable of transmitting 'literal information'. The relation between the signifier and signified is one of recording. The scene is already there and is captured mechanically which emphasizes its naturalness and objectivity. Few will even notice or question the choice of colour, clothes, position, shapes, among others in an image, and many will believe that they are by no means an addition. They exist as part of the image, as a duplication of what happened.

This superficiality or banality of reading is intriguing. If an image is a pure imitation of reality, and if what we see is what really is, then why is it that some images affect us more than others even if they depict the same reality? People ignore that they were unconsciously trained to see. Television, the press, social networks all participate in this training. They discreetly decide on what and where the viewers are supposed to see, blurring any message or meaning an image may carry. That is exactly how public opinion is manipulated. Ads are notorious for being culturally laden, but the striking revelation is that a press photograph that is believed to be a reality-like image, is also processed and constructed. Many reject this statement and believe that it is objective and neutral since it honestly depicts reality, that it bears no more development since it is analogical and continuous. In fact, this resistance emanates from a structural and ethical dilemma. In other words, it is hard to believe that the press photograph that is supposed to bring reality to the viewer is fake and distorted. Moreover, the realistic package in which the photograph is wrapped and served is talentedly made and cannot be doubted. In fact, the paradox among the photograph comes from the ability to create a coded message out of a no-code one, as from transforming something 'natural' into something cultural. Different techniques are used to impose a second meaning on the photograph before it is delivered to the viewer. These techniques are realized during the production phase, such as framing, choice, layout, and other technical treatment. They aim to encode the "photographic analogue", in Barthes terms.

What other possible interpretation an image would bear? And what makes the viewer react? The cosmic rule made it that things are created in binaries. As far as images are concerned, an image carries two complementary meanings or messages, a denoted and a connoted one. The former operates at the suprasegmental level of the image. It provides information about the event, the object, the setting, etc. Its purpose is purely communicative. The second, on the other hand, is more profound since it works on the underlying level. Its purpose is significant. The third meaning is about significance. The second and third meanings are the most significant and deeply explored within any form of representation. The symbolic (connoted) meaning, for Barthes (1977), is the obvious meaning. Obvious in the sense that it is the first meaning that comes to the viewer when reading (not looking at) an image; it is intentional, uses common symbols, passes as natural, and "comes ahead" (Barthes, 1977). While Eisenstein believes the role of the obtuse meaning lies in blurring and disguising, Barthes believes that the obtuse meaning, as he names it, is more obstinate and difficult to absorb. It transcends culture and knowledge. It does not copy anything. It is "a signifier without a signified" (Barthes, 1977). For Eisenstein "the interaction of images within the mind and feelings of the beholder, is itself dynamic. What counts most in the film is not the individual denotations of each shot, but the spectator's response to the collision of shots, an impact that should draw the audience into an ongoing emotional and intellectual experience" (Barthes, 1977). He insists that 'affect' or pathos is the most revealing criterion of a film or an image success. He believes that an image, whether still or moving, has to be reactionary. An image that does not move the viewer is pointless, insignificant. The reaction that some images cause is the consequence of this obtuse meaning that was able to reach the public conscience and shake it. Since he is interested in films, he believes that pathos is what makes people engage in crying or applause by the end of the show. The audience moves from being passive beholders to creators of meaning. Eisenstein's view on shaking the emotional consciousness of the viewer is close to Barthes' idea of the punctum in Camera Lucida. For Barthes, the punctum "stings, specks and cuts" (Barthes, 1980, p.27). Unlike 
the studium which only makes us like or dislike a photograph, the punctum wounds, traverse the viewer's mind leaving a hole behind. It is what marks the reader and makes them read the image anew as if it were the first time. It comes in the form of "a detail that fills the whole picture" (Barthes, 1980, p.45). It is that already existing anything that becomes 'something', something that provokes, triggers and shocks. Also, the punctum translates the photographer's intentions, as if it is proof of him "being there", present during the act of photographing and participating in the making of the photograph/event. The inability to name that feeling one feels after looking at some photographs is what ranks the punctum as a third meaning, it is unintelligible that it cannot be named. It is this punctum that explains why some images live within our memory more than others do. It keeps the picture alive in our mind even if we no longer look at it and it is what directly comes into our minds once we close our eyes and recall that very given image. Back to fig.2, the punctum is the silence and calmness of Emran in the middle of mayhem and disturbance. His tranquillity, which is much unusual of a boy of his age and under those circumstances, makes noise in our minds. We have always seen images of children who have survived bombings or even succumbed to them, but we were not as affected as with this image. Most of the time, those children were crying out of pain and fear, that is the normal reaction, what shocks in Emran's picture is his own reaction under the shock.

Barthes' punctum and Eisenstein's pathos is what makes most of the viewers outraged by the images of children being killed, tortured, bombarded in Syria, Palestine, Burma, or any other places where people and children are abused and mistreated. It is that effect that incites people's discontent and anger at their governments and makes them publicly express their indignation. The Arab Spring was an image era by excellence. We were submerged with images depicting the carnage of revolutions and their impact on innocent people, and the masses that went into the streets were armed with images to support their claims. The whole world was moved and engaged into action. It is that detail, punctum, or third meaning that emanates from those images, shocks the audience, and makes every parent, every person, every human being express their grief, their anger at what they see. Those people are not aware of these notions presented by Barthes or Eisenstein, they are only knowledgeable of what they see. This is the shocking effect Barthes talks about in his book.

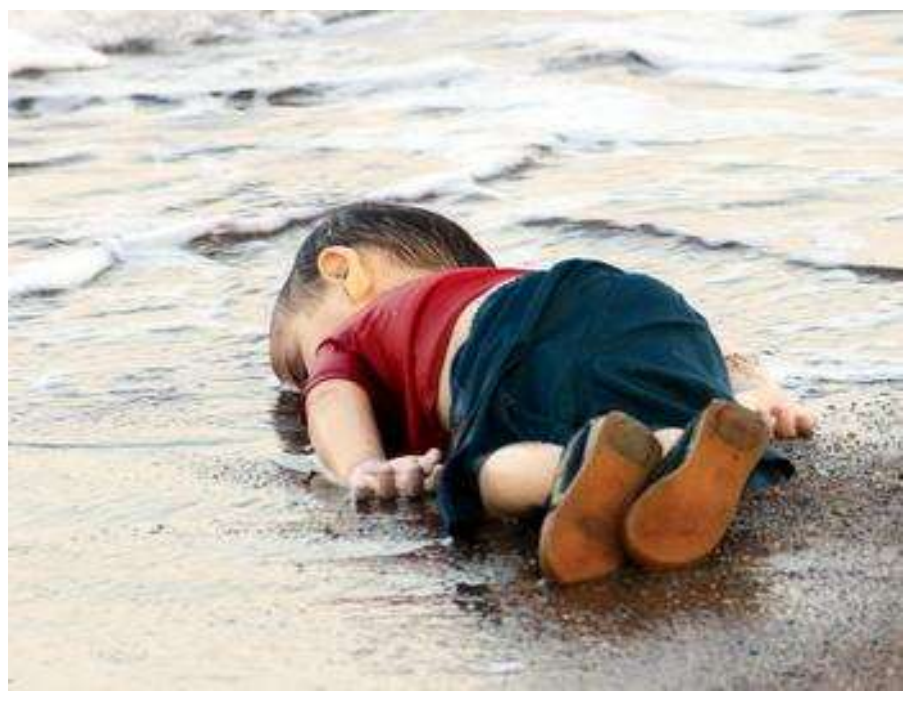

Fig.4: The lifeless body of Aylan Kurdi, Turkey (2015) (source: google)

The gut-wrenching photograph above (fig.4) is one of the images that went viral on social media and world news, stirred the world, and wounded the public conscience. It is a good example of how the image succeeds to construct public opinion and urge people to act. This image has become part of the world's collective memory. The distressing image depicts a child's lifeless body lying on the beachline of the Turkish city Bodrum. The Syrian boy drowned while trying to escape a fatality to end up in another one. The child is alone, his face down into the sand. The co-presence of two heterogeneous worlds, the world of innocence and childhood, and the perilous world of the sea are what attracts attention at first. The boy's presence is advenient to the scene. Children are not supposed to be by the sea and if it happens, they must be accompanied or at least having a good time, which is not the case here obviously. The punctum in Aylan's image is the liveliness of his clothes' colours, despite what he went through and his body's position in the image. His body seems untouched as if he is sleeping, and his head is heading the sea as if he still hopes to go back and join his family to traverse and reach the other side. Despite being a lifeless body, he was denied a decent burial. It just reminds us of people whose bodies could not be found after drowning. In most cultures, burial is an important practice to honour the deceased. Not having this 'honour' adds to the miserable fate of thousands of refugees who were the victim of an endless war. Although we have seen hundreds of similar images from different corners of the world, this image cannot be forgotten. It is the 
representation of a human tragedy, of the refugees' ordeal and children's situation in war. Aylan has become a symbol of all Syrian children whose dream of safety has turned into a nightmare.

Ranged from grief to rage, the public responses were massive. The reaction of political leaders in response to Aylan's photograph demonstrated a unified sense of dismay and disgrace. UK prime minister, David Cameron, for example, expressed his sentiment and promised to review the immigration policies. "We will fulfill our moral responsibilities", stated Cameron. Angela Merkel also invited the refugees to Germany by opening the borders, while Hilary Clinton used the photograph in her presidential campaign as an urgent situation that needs to be resolved. These politicians' responses were the result of a process of unothering the subject in the image. In other words, the unclear facial features of Aylan made parents see their own child in that lifeless body. People could see that the incident can happen to anyone and that no one is immune. The civil society's concern with Aylan's sad story was more genuine. Individuals started signing petitions, organizing fund campaigns to collect aid, as they volunteered in taking care and sheltering refugees. Indeed, the striking correlation between seeing and doing is well illustrated by this photograph which ended up being discursively potent. Such a kind of response to an image is a good example of how images can shift public opinion towards a certain issue. An incrementing feeling of shock and wish for change could be sensed though it did not last. History has always proved that public sympathy is short-lived. Before Aylan's, there was Mohamed Jamal Dourra, and after him Emran. They all activated a short wake-up call that was followed by a long 'moral sleep'. Nevertheless, this particular image has found a place in the public imaginary and moral conscience.

\section{Conclusion}

During the Arab Spring revolutions, images made the event. Whether professional or amateurish, they were ubiquitous in every single move. They have proved to have a political weight capable of shaking balances, surpassing any other visual forms. I believe that the Arab Spring would not have reached the huge number of audiences it had reached and affected without the presence and the help of images. It could have gone unnoticed by the tyrant regimes and their alibi media. The number of images produced during these revolutions and their circulation on media by different individuals and institutions was unprecedented. The Arab Spring has definitely traced the modern history and documented the different steps it went through. Therefore, a study of what images are about and how they work on people's conscience imposed itself. My paper was an attempt to point to a visual phenomenon that has emerged during the Arab Spring. It approaches the image from an intrinsic perspective. It analyses the different discourses inherent to the image and that respectively contribute to giving it a sense and significance. Through the analysis of some controversial images that had some impact during and after the Arab Spring, we get to know that images can be subversive when they make us think and not only see. I have been trying to approach the image in its relation to the public and explain why some images override the visual message to construct public opinion and bring about action. However, it cannot be forgotten that images were not the only visual medium present during these revolutions. In fact, creativity in transmitting and capturing those images made them acceptable to the audience. Any other type of 'graphic' images would have alienated and repulsed the audience rather than creating a storm of vindications and calls to interfere. In this respect, I have only focused on still images, on photographs in specific, discarding videos and other types of images. Nonetheless, videos had a great share in the circulation of news of the Arab Spring. More than that, the Arab Spring was a good occasion for artistic productions that offered an 'aesthetic' façade to a bloody reality. Such works were conspicuous and need also to be searched, approached, and analyzed further. This paper is but a first step into image reading and can be supported by future research and studies.

\section{References}

[1] Arnheim, R. (1974). Art and Visual Perception: A Psychology of the Creative Eye. University of California Press, Berkeley and Los Angeles.

[2] Barthes. R. (1977). Image Text Music. Essays selected and translated by Stephen Heath. Fontana Press, London.

[3] Barthes, R. (1977). The third meaning. Trans. Stephen Health. London: Fontana Press,

[4] Barthes, R., \& Howard, R. (1981). Camera lucida: Reflections on photography. New York: Hill and Wang.

[5] Baudelaire, C. (1955). The Mirror of Art. Ed. and trans. Jonathan Mayne. London: Phaidon. Press limited,

[6] Habermas, J. (1989), The Public Sphere: An Encyclopedia Article. In Critical theory and Society. A Reader, ed. Stephen E. Bronner and Douglas Kellner, 136-142., New York: Routledge.

[7] Khatibi, A. (1971). La Mémoire tatouée. Paris: Editions Denoël.

[8] Kress, G., Von leeuwen, T. (1996). Reading Images: The Grammar of Visual Design. Routledge, New York.

[9] Joly, M. (1994). Introduction à l'analyse de l'image. Paris : Editions Nathan,

[10] Peirce, C.S. (1894). What Is a Sign? Published in part in CP 2.281, 285, and 297-302, and in full in EP 2:4-10. Peirce Edition Project

[11] Sartre, J. P. (1936). L'imagination. PUF.

[12] Sontag, S. (1973). On photography. New York: Farrar, Straus and Giroux. 